\title{
Aortic and coronary atherosclerosis: a natural association?
}

\author{
Ernst E. van der Wall · Arnoud van der Laarse
}

Received: 6 November 2008/ Accepted: 6 November 2008/Published online: 27 November 2008

(C) The Author(s) 2008. This article is published with open access at Springerlink.com

Several studies have demonstrated an association between coronary and aortic atherosclerosis [1-7]. For instance, risk factors are similar for the development of both thoracic aortic aneurysms and other cardiovascular diseases. Coronary artery disease (CAD) is highly prevalent in patients with thoracic aortic aneurysms, with a reported prevalence of 30$70 \%$. Knowledge of the underlying cardiac pathology can minimize perioperative risk and improve patient selection. This may allow for the optimal screening, diagnosis and management of patients with this common and potentially lethal disorder. Cardiovascular imaging may play a crucial role in the early detection of the total atherosclerotic burden. The atherosclerotic burden can be used as an indicator of the extent of the atherosclerotic process in the aorta through the use of both metabolic and morphologic data. Imaging of the aorta and the aortic wall can been performed by various imaging modalities such as transesophageal echocardiography (TEE) [1, 4], radionuclide imaging [8-13], cardiovascular magnetic resonance (CMR) [14-20], and computed tomography (CT), whereby CMR and CT also allow

Editorial comment to the article by Jeltsch et al. (doi:10.1007/s10554-008-9373-6).

E. E. van der Wall $(\bowtie)$ · A. van der Laarse Department of Cardiology, Leiden University Medical Center, P.O. Box 9600, Leiden, The Netherlands e-mail: e.e.van_der_wall@lumc.nl visualization of the coronary arteries [21-36]. Latest publications using TEE have reported a significant correlation between wall changes in the thoracic aorta and angiographic extent of coronary artery stenosis in patients with severe CAD [1, 2, 4]. Tatsumi et al. [37] showed that the combination of FDG-PET/CT depicted FDG uptake commonly in the affected thoracic aortic wall. The FDG uptake site was mostly distinct from the calcification site and may possibly be located in areas of metabolic activity of atherosclerotic changes i.e. macrophages. Adame et al. [38] developed an automated technique to trace the contours of the lumen and outer boundary of the aortic wall using CMR, allowing the measurement of aortic wall thickness in axial CMR images. The used algorithm proved to be a powerful tool to automatically draw the boundaries of the aortic wall and measure aortic wall thickness in aortic wall devoid of major lesions. Maroules et al. [39] showed that blackblood CMR of aortic atherosclerosis was very reproducible. Parallel imaging at 3-Tesla permitted shorter scan time compared with conventional 1.5Tesla imaging with comparable measures of atherosclerosis extent. Malayeri et al. [40] determined the relation between aortic wall thickness and aortic distensibility with traditional cardiovascular risk factors in the multi-ethnic study of atherosclerosis (MESA) cohort. In total, 1,053 participants in MESA underwent CMR for the measurement of aortic wall thickness and aortic distensibility. The authors showed that older age and higher blood pressure 
were associated with higher aortic wall thickness and lower aortic distensibility. Decreased aortic distensibility was further associated with current smoking, African American ethnicity, and higher high-density lipoprotein cholesterol level.

Sakuta et al. [41] evaluated delayed enhancement on CT of the aortic wall of atherosclerotic aneurysms and showed delayed enhancement in 66 of 110 patients $(60 \%)$ with atherosclerotic abdominal aortic aneurysms which may therefore be associated with chronic inflammation by atherosclerosis. Mao et al. [42] showed with multidetector computed tomography (MDCT) that the ascending aortic diameter increased with age and male gender. Gender-specific and age-adjusted normal values for aortic diameters are necessary to differentiate pathologic atherosclerotic changes in the ascending aorta. Takasu et al. [5] assessed aortic atherosclerosis with electron-beam CT as an independent predictor of obstructive CAD in 76 patients. It was demonstrated that aortic plaque detected with contrast-enhanced electron-beam CT was a more consistent predictor of obstructive CAD than other independent aortic variables.

In the current issue of the International Journal of Cardiovascular Imaging, Jeltsch et al. [43] assessed aortic wall thickness using MDCT as a predictor of coronary atherosclerosis. Purpose of the study was the evaluation of the thoracic aortic wall thickness in 160 patients as a potential identifier of patients at increased risk for future cardiac events. Relationships between aortic wall thickness, sex, age, major risk factors and atherosclerotic plaque burden of the coronary arteries were studied. Higher values of maximum aortic wall thickness of the descending aorta were found in patients with coronary atherosclerosis compared to patients with same gender but excluded atherosclerosis. Aortic wall thickness of the mid-portion of the descending aorta of $3.0 \mathrm{~mm}$ or greater was associated with CAD with a specificity of $96.6 \%$ (sensitivity $27.5 \%$ ) and a positive predictive value of $93.3 \%$. For patients with two or more major risk factors and a maximum wall thickness of equal or more than $2.6 \mathrm{~mm}$ a positive predictive value of $100 \%$ was found for the presence of coronary atherosclerosis. Interestingly, $91 \%$ of the patients presenting with calcifications of the thoracic aorta also showed calcified or non-calcified plaques of coronary vessels. However, aortic wall measurements were not suitable to discriminate patients with obstructive from non-obstructive CAD.

In conclusion, the study of Jeltsch et al. [43] shows that measurement of maximum wall thickness of the descending aorta utilizing MDCT is a potential tool for detecting patients with subclinical coronary atherosclerosis. In addition, this study shows together with most of the above-mentioned CT studies - the potential of dynamic imaging of the thoracic aorta and cardiac structures and function, including the coronary arteries, with just a single MDCT scan. The images can be successfully assessed for thoracic aorta pathology, cardiac disease, coronary atherosclerosis and extracardiac pathology. The potential effect of combining measurements of aortic wall thickness at routine chest CT studies with a possible cardiovascular screening is substantial. This is in line with the so-called triple ruleout protocol allowing the simultaneous evaluation of aortic pathology, coronary atherosclerosis and pulmonary embolism [44]. With further developments of CT scanners-and more detailed insight in the prognosis of patients based on ECG-gated CT angiography findings-the MDCT technique may become the initial imaging modality for preoperative cardiac risk stratification in patients with severe aortic pathology such as thoracic aortic aneurysms, aortic dissections and advanced aortic atherosclerosis.

Open Access This article is distributed under the terms of the Creative Commons Attribution Noncommercial License which permits any noncommercial use, distribution, and reproduction in any medium, provided the original author(s) and source are credited.

\section{References}

1. Rohani M, Jogestrand T, Ekberg M et al (2005) Interrelation between the extent of atherosclerosis in the thoracic aorta, carotid intima-media thickness and the extent of coronary artery disease. Atherosclerosis 179:311-316

2. Couturier G, Voustaniouk A, Weinberger J, Fuster V (2006) Correlation between coronary artery disease and aortic arch plaque thickness measured by non-invasive Bmode ultrasonography. Atherosclerosis 185:159-164

3. Zegers ES, Gehlmann HR, Verheugt FW (2007) Acute myocardial infarction due to an acute type A aortic dissection involving the left main coronary artery. Neth Heart J 15:263-264

4. Fazio GP, Redberg RF, Winslow T, Schiller NB (1993) Transesophageal echocardiographically detected atherosclerotic aortic plaque is a marker for coronary artery disease. J Am Coll Cardiol 21:144-150 
5. Takasu J, Mao S, Budoff MJ (2003) Aortic atherosclerosis detected with electron-beam $\mathrm{CT}$ as a predictor of obstructive coronary artery disease. Acad Radiol 10:631637

6. Takasu J, Takanashi K, Naito S et al (1992) Evaluation of morphological changes of the atherosclerotic aorta by enhanced computed tomography. Atherosclerosis 97:107121

7. de Leeuw JG, Wardeh A, Sramek A, van der Wall EE (2007) Pseudo-aortic dissection after primary PCI. Neth Heart J 15:265-266

8. Bural GG, Torigian DA, Chamroonrat W et al (2006) Quantitative assessment of the atherosclerotic burden of the aorta by combined FDG-PET and CT image analysis: a new concept. Nucl Med Biol 33:1037-1043

9. van Lennep JE, Westerveld HT, van Lennep HW, Zwinderman AH, Erkelens DW, van der Wall EE (2000) Apolipoprotein concentrations during treatment and recurrent coronary artery disease events. Arterioscler Thromb Vasc Biol 20:2408-2413

10. van der Wall EE, Heidendal GA, den Hollander W, Westera G, Roos JP (1980) I-123 labeled hexadecenoic acid in comparison with thallium-201 for myocardial imaging in coronary heart disease. A preliminary study. Eur J Nucl Med 5:401-405

11. Bavelaar-Croon CD, Kayser HW, van der Wall EE et al (2000) Left ventricular function: correlation of quantitative gated SPECT and MR imaging over a wide range of values. Radiology 217:572-575

12. Bavelaar-Croon CD, Pauwels EK, van der Wall EE (2001) Gated single-photon emission computed tomographic myocardial imaging: a new tool in clinical cardiology. Am Heart J 141:383-390

13. Bax JJ, Lamb H, Dibbets P et al (2000) Comparison of gated single-photon emission computed tomography with magnetic resonance imaging for evaluation of left ventricular function in ischemic cardiomyopathy. Am J Cardiol 86:1299-1305

14. Fayad ZA (2001) The assessment of the vulnerable atherosclerotic plaque using MR imaging: a brief review. Int J Cardiovasc Imaging 17:165-177

15. van Rugge FP, Holman ER, van der Wall EE, de Roos A, van der Laarse A, Bruschke AV (1993) Quantitation of global and regional left ventricular function by cine magnetic resonance imaging during dobutamine stress in normal human subjects. Eur Heart J 14:456-463

16. Tulevski II, Hirsch A, Sanson BJ et al (2001) Increased brain natriuretic peptide as a marker for right ventricular dysfunction in acute pulmonary embolism. Thromb Haemost 86:1193-1196

17. Braun S, van der Wall EE, Emanuelsson S, Kobrin I (1996) Effects of a new calcium antagonist, mibefradil (Ro 405967), on silent ischemia in patients with stable chronic angina pectoris: a multicenter placebo-controlled study. The mibefradil international study group. J Am Coll Cardiol 27:317-322

18. Molhoek SG, Bax JJ, Bleeker GB et al (2004) Comparison of response to cardiac resynchronization therapy in patients with sinus rhythm versus chronic atrial fibrillation. Am J Cardiol 94:1506-1509
19. van der Wall EE, van Dijkman PR, de Roos A et al (1990) Diagnostic significance of gadolinium-DTPA (diethylenetriamine penta-acetic acid) enhanced magnetic resonance imaging in thrombolytic treatment for acute myocardial infarction: its potential in assessing reperfusion. Br Heart $\mathbf{J}$ 63:12-17

20. van Dijkman PR, van der Wall EE, de Roos A et al (1991) Acute, subacute, and chronic myocardial infarction: quantitative analysis of gadolinium-enhanced MR images. Radiology 180:147-151

21. Langerak SE, Vliegen HW, de Roos A et al (2002) Detection of vein graft disease using high-resolution magnetic resonance angiography. Circulation 105:328-333

22. Leber AW, Knez A, Becker A et al (2005) Visualising noncalcified coronary plaques by $\mathrm{CT}$. Int $\mathrm{J}$ Cardiovasc Imaging 21:55-61

23. Pundziute G, Schuijf JD, Jukema JW et al (2007) Noninvasive assessment of plaque characteristics with multislice computed tomography coronary angiography in symptomatic diabetic patients. Diabetes Care 30:11131119

24. Schuijf JD, Jukema JW, van der Wall EE, Bax JJ (2007) Multi-slice computed tomography in the evaluation of patients with acute chest pain. Acute Card Care 9:214-221

25. van Werkhoven JM, Schuijf JD, Jukema JW et al (2008) Anatomic correlates of a normal perfusion scan using 64slice computed tomographic coronary angiography. Am J Cardiol 101:40-45

26. Pundziute G, Schuijf JD, Jukema JW et al (2007) Prognostic value of multislice computed tomography coronary angiography in patients with known or suspected coronary artery disease. J Am Coll Cardiol 49:62-70

27. Schuijf JD, Pundziute G, Jukema JW et al (2006) Diagnostic accuracy of 64-slice multislice computed tomography in the noninvasive evaluation of significant coronary artery disease. Am J Cardiol 98:145-148

28. Schuijf JD, Wijns W, Jukema JW et al (2006) Relationship between noninvasive coronary angiography with multislice computed tomography and myocardial perfusion imaging. J Am Coll Cardiol 48:2508-2514

29. Jongbloed MR, Lamb HJ, Bax JJ et al (2005) Noninvasive visualization of the cardiac venous system using multislice computed tomography. J Am Coll Cardiol 45:749-753

30. Juwana YB, Wirianta J, Suryapranata H, de Boer MJ (2007) Left main coronary artery stenosis undetected by 64-slice computed tomography: a word of caution. Neth Heart J 15:255-256

31. Schuijf JD, Bax JJ, van der Wall EE (2007) Anatomical and functional imaging techniques: basically similar or fundamentally different? Neth Heart J 15:43-44

32. Wijpkema JS, Dorgelo J, Willems TP et al (2007) Discordance between anatomical and functional coronary stenosis severity. Neth Heart J 15:5-11

33. van de Wal RM, van Werkum JW, le Cocq d'Armandville MC et al (2007) Giant aneurysm of an aortocoronary venous bypass graft compressing the right ventricle. Neth Heart J 15:252-254

34. Henneman MM, Schuijf JD, Pundziute G et al (2008) Noninvasive evaluation with multislice computed tomography in suspected acute coronary syndrome: plaque morphology on 
multislice computed tomography versus coronary calcium score. J Am Coll Cardiol 52:216-222

35. Schuijf JD, Beck T, Burgstahler C et al (2007) Differences in plaque composition and distribution in stable coronary artery disease versus acute coronary syndromes; noninvasive evaluation with multi-slice computed tomography. Acute Card Care 9:48-53

36. Achenbach S (2008) Can CT detect the vulnerable coronary plaque? Int J Cardiovasc Imaging 24:311-312

37. Tatsumi M, Cohade C, Nakamoto Y, Wahl RL (2003) Fluorodeoxyglucose uptake in the aortic wall at PET/CT: possible finding for active atherosclerosis. Radiology 229:831-837

38. Adame IM, van der Geest RJ, Bluemke DA, Lima JA, Reiber JH, Lelieveldt BP (2006) Automatic vessel wall contour detection and quantification of wall thickness in in vivo MR images of the human aorta. J Magn Reson Imaging 24:595-602

39. Maroules CD, McColl R, Khera A, Peshock RM (2008) Assessment and reproducibility of aortic atherosclerosis magnetic resonance imaging: impact of 3-Tesla field strength and parallel imaging. Invest Radiol 43:656-662
40. Malayeri AA, Natori S, Bahrami H et al (2008) Relation of aortic wall thickness and distensibility to cardiovascular risk factors (from the multi-ethnic study of atherosclerosis [MESA]). Am J Cardiol 102:491-496

41. Sakuta A, Kimura F, Aoka Y, Aomi S, Hagiwara N, Kasanuki H (2007) Delayed enhancement on computed tomography in abdominal aortic aneurysm wall. Heart Vessels 22:79-87

42. Mao SS, Ahmadi N, Shah B et al (2008) Normal thoracic aorta diameter on cardiac computed tomography in healthy asymptomatic adults: impact of age and gender. Acad Radiol 15:827-834

43. Jeltsch M, Klass O, Klein S et al. (2008) Aortic wall thickness assessed by multidetector computed tomography as a predictor of coronary atherosclerosis. Int J Cardiovasc Imaging. doi:10.1007/s10554-008-9373-6

44. Lee HY, Yoo SM, White CS (2008) Coronary CT angiography in emergency department patients with acute chest pain: triple rule-out protocol versus dedicated coronary CT angiography. Int J Cardiovasc Imaging. doi:10.1007/ s10554-008-9375-4 